\title{
Comparação da percepção e necessidade estética de tratamento ortodôntico entre pacientes e ortodontistas nas cidades de Natal/RN e João Pessoa/PB
}

Fábio Henrique de Sá Leitão Pinheiro*, Rejane Targino Soares Beltrão*, Marcos Roberto de Freitas**, José Roberto Pereira Lauris ${ }^{\star \star \star}$, José Fernando Castanha Henriques ${ }^{\star \star \star \star}$

\begin{abstract}
Resumo
Com o objetivo de comparar a perspectiva estética e a necessidade de tratamento dos ortodontistas e de seus respectivos pacientes, nas cidades de Natal/RN e João Pessoa/PB, distribuíram-se questionários aos pacientes e profissionais locais que, por meio de ilustrações de algumas características das más oclusões, que possibilitaram uma comparação do grau de valorização da estética dentofacial entre ambos os grupos. Por meio de tabelas e testes estatísticos, conclui-se que o padrão braquifacial, o desvio da linha média e o apinhamento ântero-inferior são mais perceptíveis aos profissionais do que aos pacientes e que os profissionais apontaram uma maior necessidade de tratamento da Classe II mandibular e do padrão dolicofacial do que seus respectivos pacientes, na cidade de Natal. Enquanto que em João Pessoa o desvio de linha média é mais perceptivel aos profissionais do que aos pacientes; o tratamento da Classe II mandibular, Classe II com AFAI aumentada e sorriso gengival são mais exigidos pelos pacientes do que pelos profissionais e o tratamento do apinhamento ântero-inferior mais solicitado pelos profissionais. Demonstrando que essas diferenças constituem informações valiosas para que cada profissional conheça as expectativas de seus pacientes e, assim, proceda de forma mais esclarecedora durante seus procedimentos clínicos.
\end{abstract}

Palavras-chave: Estética. Ortodontia. Má oclusão. Análise facial.

\section{INTRODUÇÃO}

O desenvolvimento da Cirurgia Ortognática e o interesse pela Ortopedia Facial constituem o reflexo da importância atribuída à estética facial pelos ortodontistas do século XX.
Segundo Sarver e Ackerman ${ }^{9}$, inúmeras faces diferentes podem ser aceitáveis esteticamente. No entanto, algumas regras são unânimes: 1) a melhor e mais coerente forma de examinar a estética facial é pela análise tridimensional da face e,

* Mestres em Odontologia, área de concentração em Ortodontia, na FOB-USP.

** Professor Livre Docente em Ortodontia e chefe do Departamento de Odontopediatria, Ortodontia e Saúde Coletiva da FOB-USP.

*** Professor Doutor do Departamento de Odontopediatria, Ortodontia e Saúde Coletiva da FOB-USP

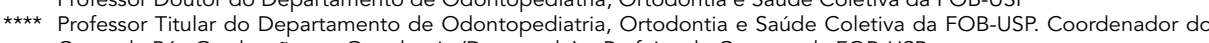
Curso de Pós-Graduação em Ortodontia (Doutorado) e Prefeito do Campus da FOB-USP. 
jamais, apenas por telerradiografias; 2) a análise frontal dos dentes anteriores é mais importante do que a de perfil, devendo-se observar sua relação com os tecidos moles e a aparência da gengiva; 3) em termos de envelhecimento, é preferivel expandir-se a se extrair.

Quanto ao aspecto facial, Chu Okuyama ${ }^{4}$ observou, em comum, algumas preferências faciais entre ortodontistas, leigos e artistas plásticos da cidade de Bauru/SP: 1) leucodermas com perfil tendendo a reto e melanodermas com suave convexidade facial; 2) protrusão nasal no gênero masculino e protrusão labial no gênero feminino.

Quanto ao aspecto dentário, há relatos que demonstram claramente a menor percepção da necessidade de tratamento por parte do leigo em relação ao ortodontista ${ }^{6,10}$, ocorrendo esta mesma tendência ao comparar-se os pacientes e seus respectivos pais ${ }^{11}$. No que se refere à decisão de se realizar uma cirurgia ortognática para a correção facial, Bell et al. ${ }^{1}$ também detectaram que os leigos mostraram-se menos rigorosos do que os cirurgiões e os ortodontistas.

Algumas características dentárias são mais perceptíveis pelos pacientes do que outras. Soh, Lew $^{12}$, De Smit e Dermaut ${ }^{5}$ listaram, em ordem de menor para maior importância, as seguintes más oclusões: 1) má oclusão de Classe I; 2) mordida aberta anterior; 3) Classe III; 4) Classe II; 5) Diastema anterior; 6) Apinhamento anterior; 7) Sobremordida profunda.

Por outro lado, parece existir muita variação quanto à percepção da necessidade de tratamento, observando-se, inclusive, algumas populações que priorizam a função em vez da estética ${ }^{3}$. Deste modo, o profissional deve estar a par das exigências estéticas locais para melhor esclarecer os benefícios e limitações do tratamento ortodôntico, tal como enfatizado por Van der Linden e Boersma ${ }^{13}$ e comprovado num estudo conduzido por Pinzan, Vargas e Janson ${ }^{7}$.

O presente estudo pretende comparar a percepção estética e de necessidade de tratamento entre os profissionais e pacientes das cidades de Natal/RN e João Pessoa/PB, no sentido de melhor direcionar o diagnóstico do ortodontista às expectativas de seus pacientes.

\section{MATERIAL E MÉTODOS}

Selecionaram-se 16 especialistas da cidade de Natal e 15 da cidade de João Pessoa, todos com mais de 2 anos de experiência clínica. Paralela-
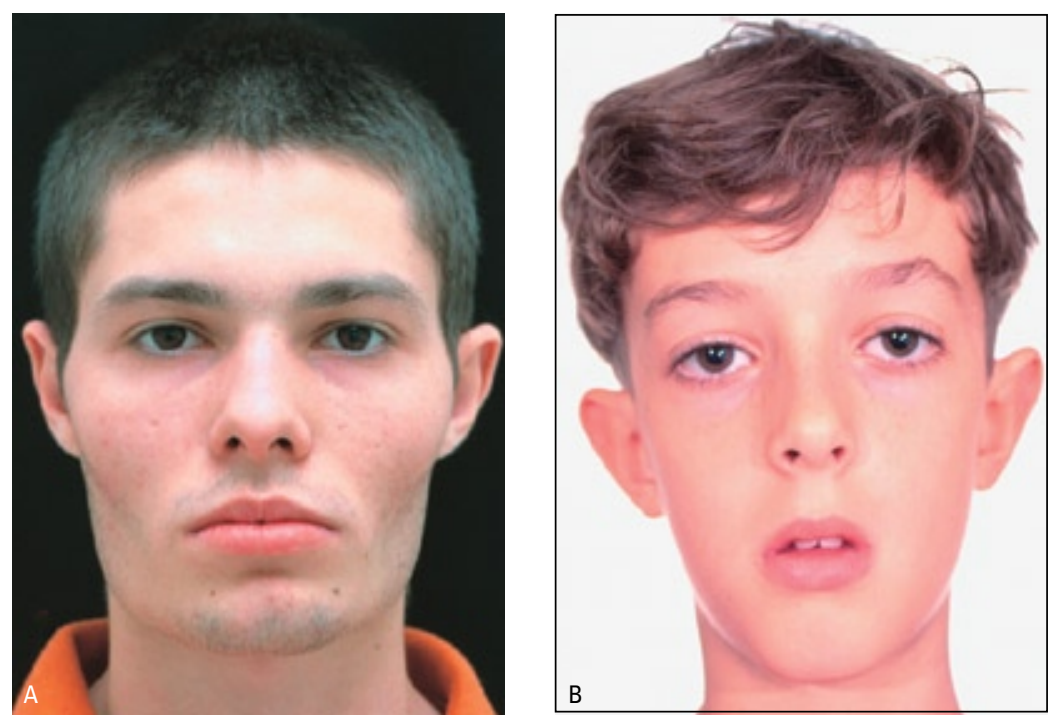

FIGURA 1 - Padrão facial (Opções: dólico, meso ou braquifacial). 

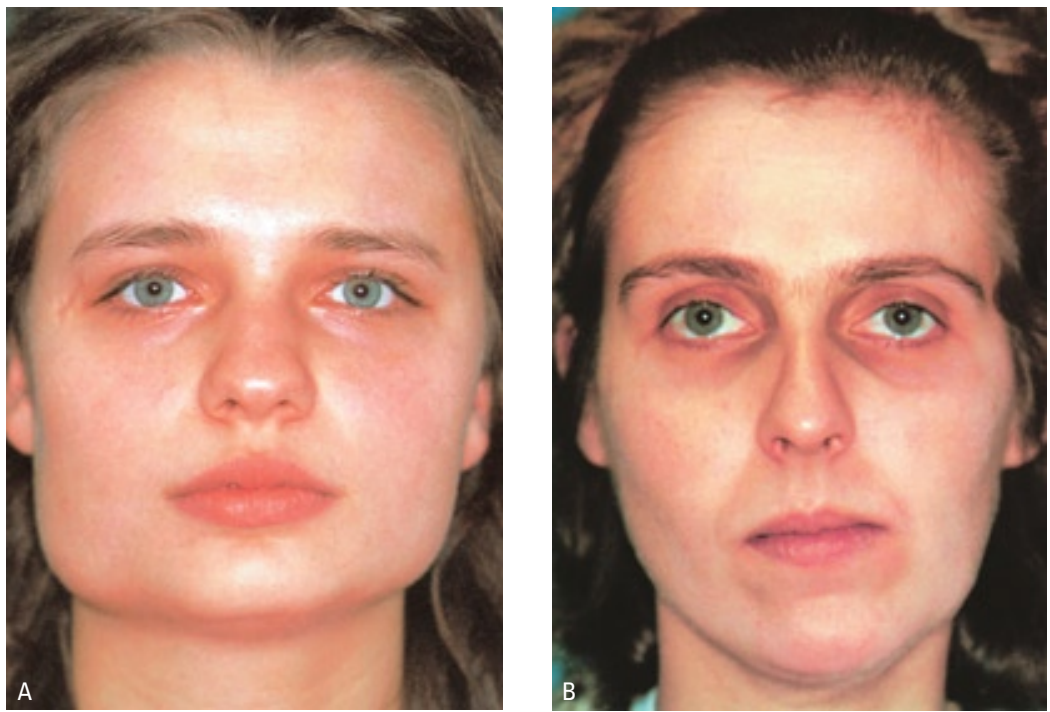

FIGURA 2 - Simetria facial (Opções: simétrica ou assimétrica) - Fonte: RAKOSI, IRMTRUD, GRABER ${ }^{8}, 1999$.
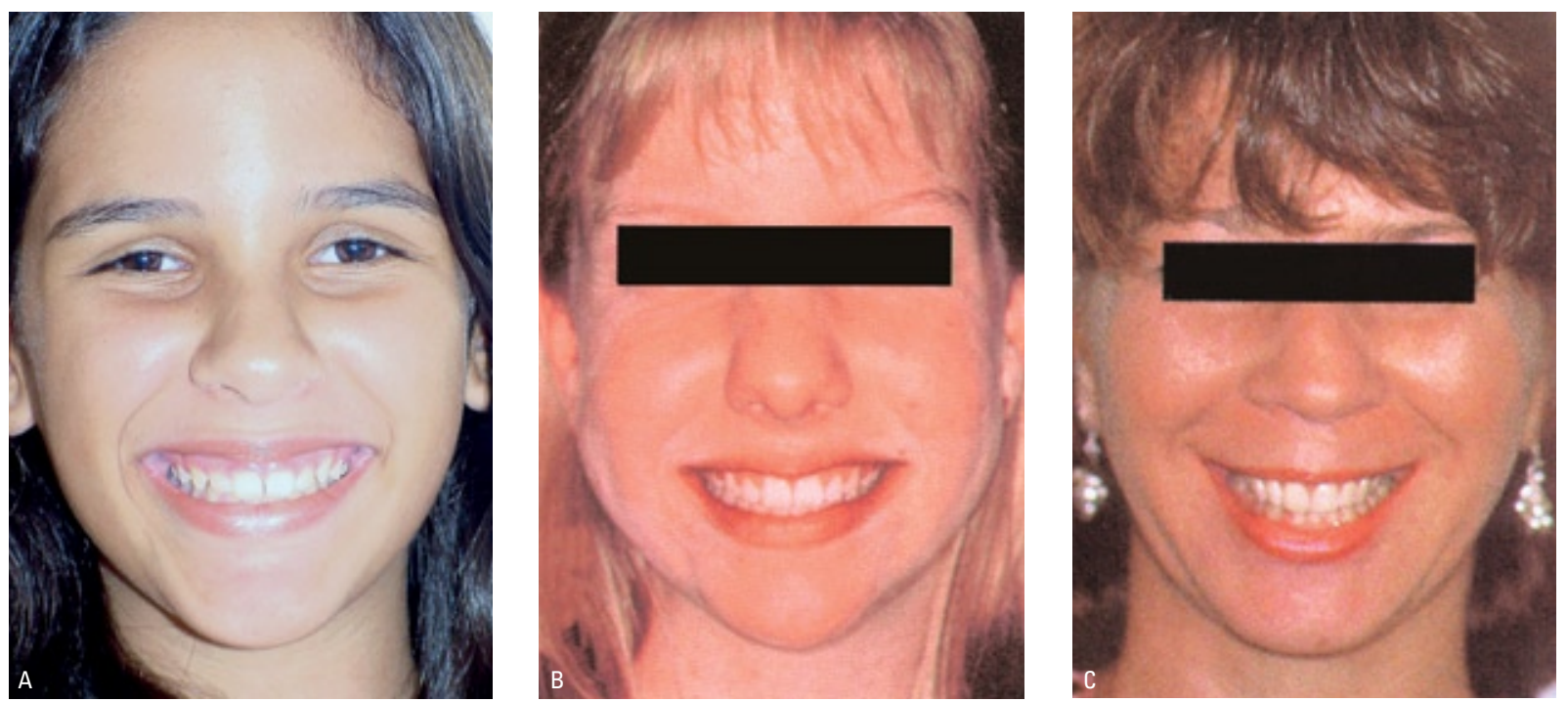

FIGURA 3 - Sorriso (Opções: gengival, satisfatório ou corredor bucal) - Fonte: VIAZIS ${ }^{14}, 1999$

mente, escolheram-se aleatoriamente 32 pacientes ortodônticos da cidade de Natal (13 do gênero masculino e 19 do feminino), com uma média de idade de 13,9 anos, e 25 da cidade de João Pessoa (11 do gênero masculino e 14 do feminino), com 14,6 anos, em média.

Ambos, ortodontistas e pacientes, preencheram questionários idênticos e adaptados sobre algumas ilustrações ${ }^{2,8}$ faciais e más oclusões, projetadas sob a forma de "slides." Basicamente, os componentes de ambos os grupos deveriam detectar o problema (percepção estética) e opinar quanto à necessidade de tratamento.

Os itens de 1 a 5 , contendo as figuras submetidas ao questionário, fornecem maiores detalhes dos problemas ortodônticos analisados.

Uma vez recolhidos os questionários, prosseguiuse com a análise estatística por meio do teste qui- 

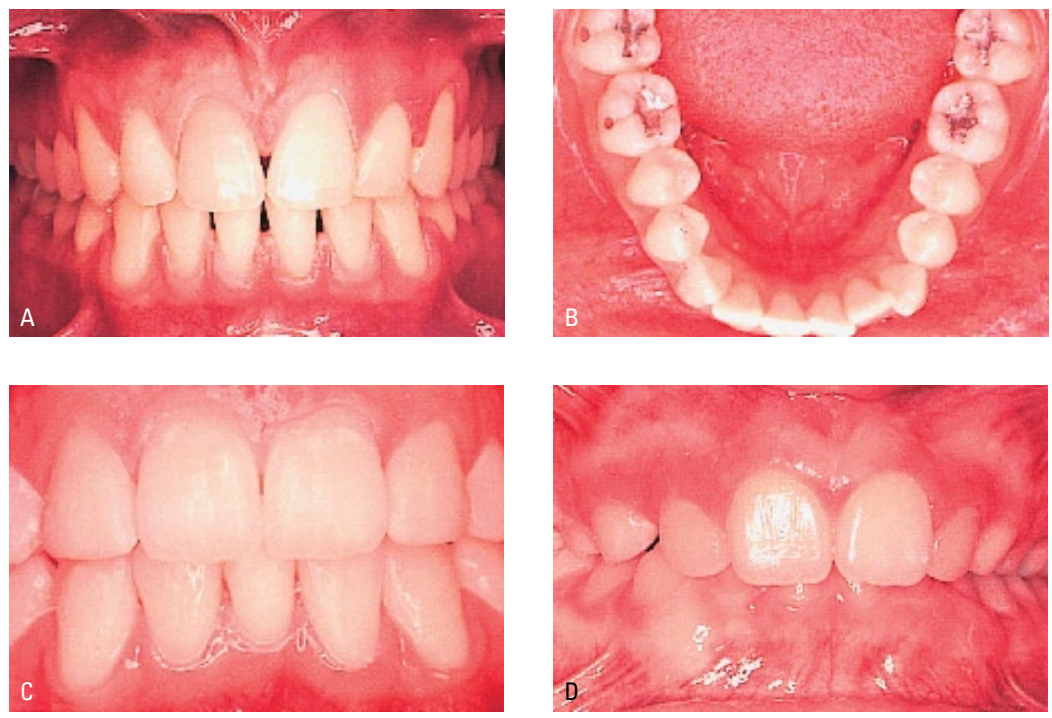

FIGURA 4 - Oclusão dentária (Opções: Diastema, apinhamento, desvio da linha média ou sobremordida profunda) Fonte: CABRERA \& CABRERA², 1997.
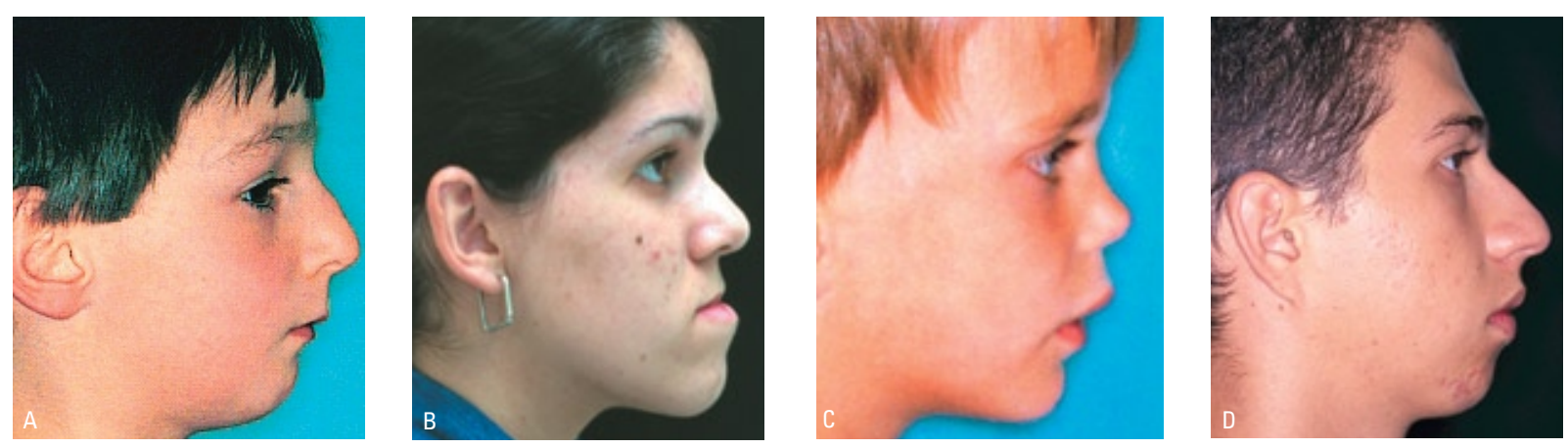

FIGURA 5 - Perfil facial (Opções: Classe II mandibular, Classe III, Classe II maxilar, Classe I ou Classe II com AFAl aumentada) - Fonte: RAKOSI, IRMTRUD, GRABER, 1999.

quadrado ou Fisher, com um nível de significância de $5 \%$. Em relação às respostas referentes à análise facial, os casos considerados satisfatórios, e portanto sem a necessidade de tratamento, foram computados como tratamento exclusivamente dentário (Dent.). Do contrário, deduzia-se que seria indicado um tratamento ortopédico ou cirúrgico (Cir.). Não se forneceram maiores informações aos profissionais, orientando-os apenas para seguir sua própria percepção estética visual, e não a realização de um plano de tratamento baseado em dados clínicos e cefalométricos.

\section{RESULTADOS}

As tabelas 1, 2, 3 e 4 reúnem todos os dados das comparações entre os ortodontistas e seus pa- cientes, incluindo-se a presença ou a ausência de significância estatística. Para uma melhor compreensão das abreviaturas, considerar que: $\mathrm{P}=$ Paciente / Est $=$ Significância estatística $/ D=$ Dolicofacial; $\mathrm{M}=$ Mesofacial; $\mathrm{B}=$ Braquifacial $/$ Dent. = Tratamento apenas dentoalveolar; $\mathrm{Cir}$. $=$ Tratamento ortopédico ou cirúrgico; NT = Não há necessidade de tratamento / Sim. = Simétrico; Assim. = Assimétrico / $\mathrm{DI}=$ Diastema $; \mathrm{AP}=$ Apinhamento $; \mathrm{LM}=$ Desvio de linha média; $\mathrm{SM}=$ Sobremordida profunda / Sat. $=$ Sorriso Satisfatório; Gen. $=$ Sorriso Gengivoso; $\mathrm{CB}$. = Sorriso com visualização do corredor bucal / $\mathrm{S}=$ Diferença estatisticamente significante; NS $=$ Sem diferença estatisticamente significante. 


\section{DISCUSSÃO}

Os ortodontistas natalenses podem ficar despreocupados quanto ao padrão tipicamente braquifacial, podendo, na maioria das vezes, instituir uma abordagem exclusivamente dentoalveolar (Quadro 1). O mesmo não se aplica aos pacientes acentuadamente dolicofaciais, assim reconhecidos pelo leigo na mesma proporção que os profissionais. Em virtude da divergência quanto à forma de tratamento do dolicofacial (Quadro 1), os profissionais de Natal devem sempre oferecer-lhe ambas as possibilidades de intervenção. Em João Pessoa, por sua vez, ambos os padrões extremos mostraram-se desagradáveis aos pacientes, chamando-se atenção ao fato de uma maior exigência de intervenção facial para o paciente dolicofacial, do que em Natal (Quadrol).

Quanto ao estudo da simetria facial (Quadro 1), os pacientes de ambas as cidades foram bastante sensíveis, reconhecendo este desvio de forma semelhante aos profissionais, inclusive em casos suaves como o da figura 2A. No que diz respeito às alternativas de tratamento, nem todos os profissionais de ambas as cidades se mostraram aptos a indicar uma intervenção cirúrgica para o caso suave da figura 2A, ao passo que aproximadamente metade de seus pacientes a exigiu (Quadro 1).

\begin{tabular}{|c|c|c|c|c|c|c|c|c|c|c|c|c|c|}
\hline & \multirow{3}{*}{ Local } & \multirow{3}{*}{ Pac. } & \multicolumn{6}{|c|}{ Percepção estética } & \multicolumn{5}{|c|}{ Necessidade de Tratamento } \\
\hline & & & \multicolumn{3}{|c|}{ Ortodontistas } & \multicolumn{2}{|c|}{ Pacientes } & $\mathbf{x}^{2}$ & \multicolumn{2}{|c|}{ Ortodontistas } & \multicolumn{2}{|c|}{ Pacientes } & $x^{2}$ \\
\hline & & & D & $\mathbf{M}$ & B & D & B & $\mathbf{p}$ & Dent & Cirúr & Dent & Cirúr & $\mathbf{p}$ \\
\hline \multirow{4}{*}{ Padrão } & \multirow{2}{*}{ Natal } & A & 0,0 & 0,0 & 100,0 & 6,3 & 65,6 & $0,028^{*}$ & 62,5 & 37,5 & 53,1 & 46,9 & 0,537 \\
\hline & & B & 100,0 & 0,0 & 0,0 & 93,8 & 3,1 & 0,612 & 0,0 & 100,0 & 25,0 & 75,0 & $0,034^{*}$ \\
\hline & \multirow{2}{*}{ J.P } & A & 0,0 & 0,0 & 100,0 & 0,0 & 20,0 & 0,112 & 64,3 & 35,7 & 86,7 & 13,3 & 0,159 \\
\hline & & B & 100,0 & 0,0 & 0,0 & 100,0 & 0,0 & 1,000 & 0,0 & 100,0 & 8,7 & 91,3 & 0,402 \\
\hline & \multirow{2}{*}{ Local } & \multirow{2}{*}{ Pac. } & \multicolumn{3}{|c|}{ Ortodontistas } & \multicolumn{2}{|c|}{ Pacientes } & $x^{2}$ & \multicolumn{2}{|c|}{ Ortodontistas } & \multicolumn{2}{|c|}{ Pacientes } & $\mathbf{x}^{2}$ \\
\hline & & & Simétr & & sssimétr & Simétr & Assimétr & $\mathbf{p}$ & Dent & Cirúr & Dent & Cirúr & $\mathbf{p}$ \\
\hline \multirow{4}{*}{ Simetria } & \multirow[t]{2}{*}{ Natal } & A & 33,3 & & 66,7 & 46,9 & 53,1 & 0,381 & 50,0 & 50,0 & 46,9 & 53,1 & 0,845 \\
\hline & & B & 0,0 & & 100,0 & 3,1 & 96,9 & 1,000 & 0,0 & 100,0 & 6,3 & 93,7 & 1,000 \\
\hline & \multirow[t]{2}{*}{ J.P. } & A & 50,0 & & 50,0 & 52,2 & 47,8 & 0,898 & 64,3 & 35,7 & 52,17 & 47,8 & 0,471 \\
\hline & & B & 0,0 & & 100,0 & 17,4 & 82,6 & 0,088 & 6,7 & 93,3 & 17,4 & 82,6 & 0,339 \\
\hline
\end{tabular}

QUADRO 1 - Comparação, em porcentagem, da percepção e da necessidade de tratamento com relação ao padrão e simetria faciais, entre os ortodontistas e pacientes das cidades do Natal/RN e João Pessoa/PB.

*Diferença estatisticamente significante entre ortodontistas e pacientes $(P<0,05)$.

\begin{tabular}{|c|c|c|c|c|c|c|c|c|c|c|c|c|c|c|c|c|}
\hline & \multirow{3}{*}{ Local } & \multirow{3}{*}{ Pac. } & \multicolumn{7}{|c|}{ Percepção estética } & \multicolumn{7}{|c|}{ Necessidade de tratamento } \\
\hline & & & \multicolumn{3}{|c|}{ Ortodontistas } & \multicolumn{3}{|c|}{ Pacientes } & \multirow{2}{*}{$\begin{array}{c}\mathbf{x}^{2} \\
\mathbf{p}\end{array}$} & \multicolumn{3}{|c|}{ Ortodontistas } & \multicolumn{3}{|c|}{ Pacientes } & \multirow{2}{*}{$\begin{array}{l}\mathbf{x}^{2} \\
\mathbf{p}\end{array}$} \\
\hline & & & Gen & CB & Sat & Gen & CB & Sat & & Dent & Cirúr & Não & Dent & Cirúr & Não & \\
\hline \multirow{6}{*}{ Sorriso } & \multirow{3}{*}{ Natal } & A & 100,0 & 0,0 & 0,0 & 96,8 & 0,0 & 3,2 & 1,000 & & 68,8 & 31,2 & & 77,4 & 22,6 & 0,518 \\
\hline & & B & 0,0 & 0,0 & 100,0 & 0,0 & 0,0 & 100,0 & 1,000 & 0,0 & 0,0 & 100,0 & 0,0 & 0,0 & 100,0 & 1,000 \\
\hline & & C & 0,0 & 87,5 & 12,5 & 0,0 & 68,8 & 31,2 & 0,157 & & 43,8 & 56,2 & & 37,5 & 62,5 & 0,676 \\
\hline & \multirow{3}{*}{ J.P } & A & 93,3 & 0,0 & 6,7 & 100,0 & 0,0 & 0,0 & 0,200 & & 38,5 & 61,5 & & 78,3 & 21,7 & $0,017^{*}$ \\
\hline & & $B$ & 0,0 & 0,0 & 100,0 & 0,0 & 0,0 & 100,0 & 1,000 & 0,0 & 0,0 & 100,0 & 0,0 & 0,0 & 100,0 & 1,000 \\
\hline & & $C$ & 0,0 & 42,9 & 57,1 & 0,0 & 60,9 & 39,1 & 0,286 & & 14,3 & 85,7 & & 36,4 & 63,6 & 0,149 \\
\hline
\end{tabular}

QUADRO 2 - Comparação, em porcentagem, da percepção e da necessidade de tratamento entre os ortodontistas e pacientes das cidades do Natal/RN e João Pessoa/PB, quanto à estética do sorriso. As células vazias condizem com a ausência de tal alternativa nos questionários.

${ }^{*}$ Diferença estatisticamente significante entre ortodontistas e pacientes $(P<0,05)$. 


\begin{tabular}{|c|c|c|c|c|c|c|c|c|c|c|c|c|c|c|c|c|c|c|}
\hline & \multirow{3}{*}{ Local } & \multirow{3}{*}{ Pac. } & \multicolumn{11}{|c|}{ Percepção estética } & \multicolumn{5}{|c|}{ Necessidade de tratamento } \\
\hline & & & \multicolumn{5}{|c|}{ Ortodontistas } & \multicolumn{5}{|c|}{ Pacientes } & \multirow{2}{*}{$\begin{array}{l}\mathbf{x}^{2} \\
\mathbf{p}\end{array}$} & \multicolumn{2}{|c|}{ Ortodontistas } & \multicolumn{2}{|c|}{ Pacientes } & \multirow{2}{*}{$\begin{array}{l}\mathbf{x}^{2} \\
\mathbf{p}\end{array}$} \\
\hline & & & Sat & DI & AP & LM & SM & Sat & DI & AP & LM & SM & & Dent & Não & Dent & Não & \\
\hline \multirow{8}{*}{ Oclusão } & \multirow{4}{*}{ Natal } & A & 0 & 100 & 0 & 0 & 0 & 16 & 84 & 0 & 0 & 0 & 0,150 & 100 & 0 & 81 & 19 & 0,082 \\
\hline & & B & 0 & 0 & 100 & 0 & 0 & 44 & 0 & 56 & 0 & 0 & $0,001^{*}$ & 69 & 31 & 44 & 56 & 0,102 \\
\hline & & C & 0 & 0 & 0 & 100 & 0 & 50 & 3 & 10 & 37 & 0 & $0,001^{*}$ & 50 & 50 & 38 & 62 & 0,433 \\
\hline & & D & 0 & 0 & 0 & 0 & 100 & 3 & 0 & 3 & 0 & 94 & 0,583 & 100 & 0 & 97 & 3 & 0,660 \\
\hline & \multirow{4}{*}{ J.P. } & A & 0 & 100 & 0 & 0 & 0 & 0,0 & 0 & 100 & 0 & 0 & 1,000 & 73 & 27 & 82 & 18 & 0,538 \\
\hline & & B & 0 & 0 & 100 & 0 & 0 & 14 & 0 & 86 & 0 & 0 & 0,267 & 93 & 7 & 60 & 40 & $0,033^{*}$ \\
\hline & & C & 0 & 0 & 0 & 100 & 0 & 29 & 0 & 0 & 71 & 0 & 0,061 & 43 & 57 & 40 & 60 & 0,868 \\
\hline & & D & 0 & 0 & 0 & 0 & 100 & 0 & 0 & 0 & 0 & 100 & 1,000 & 100 & 0 & 100 & 0 & 1,000 \\
\hline
\end{tabular}

QUADRO 3 - Comparação, em porcentagem, da percepção e da necessidade de tratamento entre os ortodontistas e pacientes das cidades do Natal/RN e João Pessoa/PB, quanto à oclusão dentária.

${ }^{*}$ Diferença estatisticamente significante entre ortodontistas e pacientes $\mathrm{P}<0,05$.

\begin{tabular}{|c|c|c|c|c|c|c|c|}
\hline & & \multicolumn{5}{|c|}{ Necessidade de Tratamento } \\
\hline
\end{tabular}

QUADRO 4 - Comparação, em porcentagem, da necessidade de tratamento entre os ortodontistas e pacientes das cidades do Natal/RN e João Pessoa/PB, quanto ao perfil facial. As células vazias condizem com a ausência de tal alternativa nos questionários.

*Diferença estatisticamente significante entre ortodontistas e pacientes $(\mathrm{P}<0,05)$.

A postura destes profissionais parece estar correta, uma vez que a assimetria apresentada (Fig. 2A) não sugere uma discrepância esquelética, e sim muscular. Isto reforça a importância de uma boa orientação aos pacientes e seus responsáveis ${ }^{1-14}$.

Em se tratando do aspecto do sorriso (Quadro 2), profissionais e pacientes de Natal valorizaram igualmente o sorriso da figura 3B e reconheceram, na mesma proporção, a presença do sorriso gengival e do excesso de visualização do corredor bucal nas figuras 3A e 3C, respectivamente. Ambos os grupos (pacientes e profissionais) indicaram, em sua maioria, um tratamento efetivo para o sorriso gengival, enquanto as opiniões se dividiram igualmente quanto à necessidade de tratamento para o excesso de corredor bucal. Este aspecto, portanto, sempre deve ser discutido entre profissionais e pacientes $^{1-14}$. Observou-se o mesmo em João Pessoa (Quadro 2), com exceção da correção efetiva do sorriso gengival que, curiosamente, foi mais reivindicada pelos pacientes do que indicada pelos profissionais que, a partir de então, deverão abordar este assunto com maior interesse $\mathrm{e}^{7,13}$.

O diastema ou black space (Fig. 4A) foi igualmente percebido por pacientes e profissionais nas duas cidades estudadas, sendo indicada, em ambos os grupos, a correção ortodôntica (Quadro 3). $\mathrm{O}$ apinhamento ântero-inferior (Fig. 4B), em Natal, foi mais diagnosticado pelos profissionais do que pelos pacientes, tal como é comumente descrito na literatura ${ }^{5,12}$. 
Entretanto, a necessidade de tratamento desta má oclusão foi igualmente apontada por ambos os grupos analisados (Quadro 3). Em João Pessoa, por sua vez, pacientes e profissionais igualmente reconheceram o apinhamento ântero-inferior, embora estes últimos demonstraram um maior interesse em sua correção ortodôntica. Isto é aceitável, desde que os profissionais esclareçam que este tratamento é meramente estético e, muitas vezes, passível de recidiva, uma vez que a irregularidade não é muito acentuada e compatível com o apinhamento terciário, resultante da maturação craniofacial. Já o desvio de linha média (Fig. 4C), como já se esperava, foi mais perceptível aos profissionais, tanto em Natal quanto em João Pessoa (Quadro 3). Daqueles profissionais e pacientes que reconheceram essa alteração, aproximadamente metade indicou o tratamento ortodôntico, o que ressalta a importância de discutir-se, com os pacientes, a intenção e a viabilidade de sua correção ${ }^{7,13}$.

A sobremordida (Fig. 4D) foi unanimemente destacada por pacientes e profissionais em ambas as cidades, sendo exigida sua correção na maioria dos casos (Quadro 3). Esta foi, sem dúvida, a má oclusão dentária mais preocupante aos pacientes, tal como também observado por De Smit, Dermaut ${ }^{5}$; Soh e Lew ${ }^{12}$.

Quanto aos perfis analisados (Quadro 4), os profissionais natalenses demonstraram um maior interesse no tratamento cirúrgico/ortopédico do caso da figura 5A (Classe II por deficiência mandibular) do que seus respectivos pacientes, algo extremamente compreensivel haja visto o conhecimento profissional das características das más oclusões ${ }^{1,6,10,11}$. Em João Pessoa, não se registraram diferenças significantes entre pacientes e profissionais quanto a este quesito (Quadro 4). Em ambas as cidades, não houve divergência na opinião dos profissionais e pacientes a respeito da necessidade cirúrgica do caso da figura 5B (Classe III esquelética no gênero feminino). Quanto ao caso da figura 5C (Classe II maxilar), os profissionais e pacientes de Natal ficaram divididos, havendo uma tendência destes primeiros a priorizarem uma abordagem ortopédica/cirúrgica para o caso (Quadro 4). Em
João Pessoa, esta tendência ficou muito mais clara em ambos os grupos. Com relação ao caso da figura 5D (Classe II com AFAI aumentada), os profissionais e pacientes de Natal se mostraram igualmente divididos quanto à opção de tratamento: cirúrgica, com alteração facial, ou meramente dentoalveolar, sem alterações faciais (Quadro 4). Já os pacientes paraibanos demonstraram um maior interesse no tratamento cirúrgico (facial) deste caso do que seus respectivos profissionais, o que é perfeitamente compreensível, em se tratando de um caso cuja proeminência nasal parece responder por boa parte da convexidade facial e a oclusão geralmente se encontra compensada nestes casos (Quadro 4).

Não restam dúvidas de que questionários objetivos, contendo as alternativas de resposta, podem induzir à obtenção de determinados resultados. Embora esta seja uma limitação deste trabalho, ficaria estatisticamente inviável realizar-se uma comparação deste tipo via questionários subjetivos. Embora estes resultados não sejam soberanos, fornecem uma visão geral das tendências de estética e de necessidade de tratamento nas populações autóctones estudadas.

Quanto aos resultados obtidos, portanto, não cabem discussões sobre a melhor conduta para cada caso, mas apenas divulgar as expectativas médias dos pacientes analisados para que seus profissionais possam melhor orientá-los, tanto durante a consulta inicial, quanto no decorrer do tratamento.

\section{CONCLUSÕES}

Por meio dos resultados obtidos e da metodologia empregada, pôde-se admitir as seguintes conclusões:

Em Natal/RN:

1) O padrão braquifacial, o desvio de linha média e o apinhamento ântero-inferior são mais percebidos pelos profissionais do que pelos pacientes;

2) Os profissionais apontaram uma maior necessidade de tratamento da Classe II mandibular e do padrão dolicofacial do que seus respectivos pacientes.

Em João Pessoa/PB:

1) O desvio de linha média é mais percebido 
pelos profissionais do que pelos pacientes;

2) O tratamento da Classe II mandibular, Classe II com AFAI aumentada e sorriso gengival é mais exigido pelos pacientes do que pelos profissionais;

3) O tratamento do apinhamento ântero-inferior foi mais solicitado pelos profissionais.

\title{
Comparing the perception and esthetic need of orthodontic treatment between patients and orthodontists from Natal/RN and João Pessoa/PB.
}

\begin{abstract}
This work aimed to compare the sense of esthetics, and the capacity to deem the need of orthodontic treatment, between orthodontists and their respective patients in the cities of Natal-RN and João Pessoa-PB, Brazil. Questionnaires containing illustrations of certain aspects of malocclusions (facial patterns, facial asymmetries, unbalanced profiles, smiles and intraoral views) were handed out to patients and local professionals in order to ease a comparision of the esthetic valorization degree between both of these groups. Tables and statistic tests demonstrated the existing differences and brought about important information for the clinician to recognize the patient's esthetic perspectives, leading to a better mutual understanding throughout the treatment.
\end{abstract}

Key words: Esthetics. Orthodontics. Malocclusion. Facial analysis.

\section{REFERÊNCIAS}

1. BELL, R. et al. Perceptions of facial profile and their influence on the decision to undergo orthognathic surgery. Am J Orthod, St. Louis, v. 88, no. 4, p. 323-332, 1985.

2. CABRERA, C. A. G.; CABRERA, M. C. Ortodontia clínica I e II Curitiba: Produções Interativas, 1997.

3. COYNE, R.; WOODS, M.; ABRAMS, R. The community and orthodontic care. Partll: Community perceived importance of correcting various dentofacil anomalies. Aust Orthod J, Brisbane, v.15, no. 5, p. 289-295, 1995.

4. CHU OKUYAMA, C. Preferência do perfil facial tegumentar, jovens leucodermas, melanodermas e xantodermas de ambos os sexos avaliados por ortodontistas, leigos e artistas plásticos. 1995. Dissertação (Mestrado)-Faculdade de Odontologia de Bauru, Bauru, 1995.

5. DE SMIT, A.; DERMAUT, L. Soft-tissue profile preference. Am J Orthod Dentofacial Orthop, St. Louis, v. 86, no.1, p. 67-73. July 1984.

6. ESPELAND, L. V. et al. Perception of personal dental appearance in young adults: relationships between occlusion, awareness and satisfaction. Am J Orthod Dentofacial Orthop, St. Louis, v. 100, no. 3, p. 234-241, 1991.

7. PINZAN, A.; VARGAS, J.; JANSON, G. R. P. O paciente ortodôntico quanto ao seu grau de informação e motivação, e suas expectativas acerca do tratamento. Ortodontia, São Paulo, v. 30, n. 3, p. 40-44.1997.

8. RAKOSI, T.; IRMTRUD, J.; GRABER, T. M. Ortodontia e ortopedia facial: diagnóstico. Porto Alegre: Artmed, 1999.
9. SARUER, D. M.; ACKERMAN, J. L. Orthodontic about face: the re-emergence of the esthetic paradign. Am J Orthod Dentofacial Orthop, St. Louis, v.117, no. 5, p. 575-576, 2000.

10. SHEATS, R. D. Oclusal traits and perception of orthodontic need in eight grade students. Angle Orthod, Appleton, v. 68, no. 2, p.107-114, 1996.

11. SHEATS, R. D.; GILBERT, G. H. Pilot study comparing parent's and third-grade school children's attitudes toward braces and perceived need for braces. Community Dent Oral Epidemiol, Copenhagen, v. 23, no.1, p. 36-43, 1995.

12. SOH, G.; LEW, K. K. K. Assessement of orthodontic treatment needs by teenagers in an Asian community in Singapore. Community Dent Health, London, v. 9, no. 1, p. 57-62, 1992.

13. VAN DER LINDEN, F. P. G. M.; BOERSMA, H. Indications and contraindications for treatment. In:_. Diagnosis and treatment planning in dentofacial orthodontics. Chicago: Quintessence, 1987. p.165-183.

14. VIAZIS, A. D. Atlas de ortodontia avançada: um guia para a eficiência clínica. São Paulo: Ed. Santos, 1999.

Endereço para correspondência

Rejane Targino Soares Beltrão

Rua Otávio Pinheiro Brisola, n6-65, apto. 74, Ed.Tapajós

Vila Universitária

CEP: $17.012-100$

Bauru - SP

E-mail: rejanetsb@uol.com.br 